\title{
Primigestas
}

Autor: Ivan Humberto Sanches

Orientador: Prof. Dr. José Carlos Peraçoli

Tese apresentada no Departamento de Ginecologia e Obstetrícia da Faculdade de Medicina de Botucatu - UNESP em 22/11/99.

Introdução: A literatura tem enfatizado que a melhor metodologia para acompanhar o dinâmico processo do trabalho de parto é o uso de registro gráfico. Esse registro, denominado de partograma, avalia de maneira simples e prática, a evolução da dilatação cervical e a descida da apresentação.

Objetivos: O presente estudo teve como objetivo avaliar a eficácia de dois partogramas diferentes na assistência clínica ao parto.

Metodologia: Foram comparados o partograma utilizado na maternidade do Hospital das Clínicas da Faculdade de Medicina de Botucatu - de Philpott \& Castle (partograma A) e o proposto pelo Centro Latino-americano de Perinatologia (Partograma B). A população estudada foi constituída de 256 parturientes primigestas, submetidas à avaliação pelos dois partogramas, e divididas, de acordo com a via de parto, em quatro grupos: Grupo I - houve concordância - parto vaginal, Grupo II - houve concordância - cesariana, Grupo III - houve discordância, pelo partograma A parto vaginal e pelo partograma B cesariana, Grupo IV - houve discordância, pelo partograma A cesariana e pelo partograma B parto via vaginal.

Resultados: A análise dos resultados mostrou concordância entre os partogramas A e B em 90,6\% dos casos. Variáveis como idade materna, idade gestacional, integridade das membranas ovulares, presença de mecônio e peso do recém-nascido, isolado ou em relação à idade gestacional, não influenciaram o resultado nos dois partogramas.

Conclusões: Na maioria dos casos, os partogramas indicaram a mesma via de parto, portanto, apresentaram a mesma eficácia na assistência clínica ao parto. Entretanto, por ser de maior praticidade em sua aplicação, sugerimos que o partograma de Philpott \& Castle continue a ser utilizado em nossa maternidade e divulgado em outros centros de assistência às parturientes.

Palavras-chave: Partograma. Resolução da gravidez. Parto normal. Cesariana.

\section{Estudo do Tratamento Cirúrgico de 33 Pacientes Portadoras de Prolapso Vaginal Pós-histerectomia}

Autor: Luciano Silveira Pinheiro

Tese para Professor Titular de Ginecologia e Obstetrícia da Maternidade-Escola da Faculdade de Medicina da Universidade Federal do Ceará no dia 23/6/98.

O estudo de 33 pacientes submetidas a cirurgias para correção do prolapso vaginal pós-histerectomia, realizadas na Maternidade-Escola da Universidade Federal do Ceará, no período de 1973 a 1997, com obedecimento a protocolo previamente estabelecido e operadas unicamente pelo autor, mostrou que a idade do grupo variou de 37 a 81 anos (média de 58 anos), com prevalência em multíparas - mais de três partos $(84,8 \%)$ e paridade média de 6 . Das 33 pacientes, 13 tinham a histerectomia abdominal como cirurgia prévia e 20 , a vaginal. O tempo de aparecimento da distopia após a histerectomia variou de 10 dias a 288 meses (média de 35,5 meses). A abordagem pela via vaginal (colporrafia anterior e posterior ampliadas e perineoplastia) como primeira intervenção corretiva foi levada a efeito em 24 oportunidades, não apresentando recidivas até o período do acompanhamento. A enterocele e a retocele quando presentes, foram corrigidas isoladamente por via baixa, com o emprego das técnicas vigentes. A operação de Brady foi realizada cinco vezes, com três recidivas; a de Burch, duas vezes, ambas recidivando. As cirurgias corretivas das falhas foram feitas por via vaginal. O tempo cirúrgico variou de 45 a 150 minutos (média de 90 minutos). Utilizou-se a anestesia peridural 30 vezes e a raquianestesia, 3. Nenhuma paciente foi submetida a transfusão de sangue. A média de permanência hospitalar foi de três dias. Em uma paciente houve lesão acidental e superficial da parede anterior da bexiga por ocasião da dissecção, que foi suturada em dois planos, por pontos separados, com catgut cromado 00, com evolução satisfatória. Detectou-se uma vez infecção urinária baixa, tratada eficazmente com ampicilina por via oral, durante uma semana. A retenção urinária no pós-operatório imediato ocorreu duas vezes, sendo solucionada com medidas conservadoras (exercício de fechamento e abertura da sonda vesical de $4 / 4$ horas, durante 10 minutos, cobertura antibiótica com ampicilina e emprego de diazepam, $20 \mathrm{mg}$ por via oral ao dia). A incontinência urinária de esforço foi relatada tardiamente, juntamente com o diagnóstico de uretrocele do primeiro grau. O encurtamento vaginal foi observado cinco vezes, embora não impedindo o ato sexual. O período de acompanhamento ambulatorial variou de 1 a 12 anos, com o tempo médio de 5 anos. Em nenhuma das pacientes houve queixas expressivas em relação aos resultados das operações corretivas da distopia pós-histerectomia.

Palavras-chave: Prolapso genital. Incontinência urinária de esforço. Elitrocele. 